\title{
AVANÇOS NA FRUTICULTURA TROPICAL NO BRASIL ${ }^{1}$
}

\author{
LAURA MARIA MOLINA MELETTI ${ }^{2}$, ALOÍSIO COSTA SAMPAIO ${ }^{3}$, \\ CARLOS RUGGIERO ${ }^{4}$
}

RESUMO - Os principais aspectos que marcaram a evolução técnica das culturas do abacaxizeiro, mamoeiro e maracujazeiro no Brasil foram discutidos. Em abacaxizeiro, tem-se constatado uma inovação no sistema de comercialização da cv. Smooth Cayenne, que consiste no uso de caixas de papelão ondulado para o mercado interno, cujo objetivo é propiciar uma garantia de sabor inserida em uma marca. O recente lançamento de cultivares resistentes à fusariose, pela Embrapa (Imperial e Vitória) e IAC (Fantástico), traz novas perspectivas de produtividade. Em maracujazeiro, a maior contribuição aos pomares foi dada pelo melhoramento genético, inicialmente voltado apenas para ampliação da produtividade da cultura. No início dos anos 2000, o lançamento das primeiras cultivares de maracujá - mais produtivas e com qualidade de fruta diferenciada para os dois segmentos de mercado (frutas frescas e agroindústria), transformou o cenário produtivo brasileiro. Com a criação de um sistema organizado de produção e comercialização de sementes e mudas selecionadas, ampliou-se significativamente a qualidade dos pomares. Atualmente, a disponibilidade de novas cultivares tolerantes à virose (VEFM) e cultivares regionais passou a representar um diferencial para a cultura. Em mamoeiro, destaca-se a ocorrência do Mosaico do Mamoeiro (Monte Alto-SP, 1967), que determinou a migração da cultura pelo Estado e sua expulsão para outros estados, até sua fixação na Bahia e no Espírito Santo, os maiores produtores nacionais. Comparam-se as técnicas utilizadas nos diferentes períodos de produção, antes e depois do surgimento do mosaico, que permitiram ao Brasil lançar-se no mercado externo, tornando-se o maior exportador mundial de mamão, com lavouras produtivas e frutos de ótima qualidade. Nesta evolução, soma-se a contribuição do melhoramento genético, que disponibilizou sementes de alta qualidade, com reflexos nas práticas culturais e de propagação. São apresentadas de colheita e de pós-colheita diferenciadas que resultaram em melhorias no padrão de qualidade das frutas exportadas para o mercado europeu e norte-americano.

Termos de indexação: avanços na fruticultura, abacaxi, mamão, maracujá, tecnologia de produção.

\section{PROGRESS IN THE BRAZILIAN TROPICAL FRUITCULTURE}

ABSTRACT - The main aspects that defined the evolution of technical crops of pineapple, papaya and passion fruit in Brazil have been discussed. In pineapple, it has been observed an innovative commercialization system of the Smooth Cayenne cultivar, which is the use of corrugated cardboard boxes for the domestic market, whose aim is to provide a flavor guarantee introduced into a brand. The recent release of cultivars resistant to fusariosis, by Embrapa (Imperial and Victoria) and IAC (Fantastico) brings new perspectives for productivity. In passion fruit, the greatest contribution to the orchards was given by genetic breeding, initially focused only to increase crop productivity. In the early 2000, the launch of the first cultivars of passion fruit - more productive and with fruit quality distinguished for two different market segments (fresh fruits and agribusiness), transformed the Brazilian productive scenario. By creating an organized system of production and commercialization of selected seeds and seedlings, increased significantly the quality of the orchards. Nowadays, the availability of new cultivars tolerant to virus (VEFM) and regional varieties started to represent a difference for the culture. In papaya, stands out the occurrence of the Papaya Tree Mosaic (Monte Alto, SP, 1967), which determined the migration of culture by the state and their expulsion to other states, until its settling in Bahia and Espirito Santo, the largest national producers. It was compared the techniques used in different production periods, before and after the emergence of the mosaic, which allowed Brazil to set out on the international market, becoming the largest exporter of papaya, with produc-

\footnotetext{
${ }^{1}$ Palestra Sinfruit 215 - Simpósio Internacional de Fruticultura - Avanços na Fruticultura (17 a 21 Outubro)

${ }^{2}$ Dra $^{\mathrm{a}}$., Pesquisadora Científica, INSTITUTO AGRONÔMICO, Caixa Postal 28, CEP 13.012-970, Campinas- SP.

E-mail: lmmm@iac.sp.gov.br

${ }^{3}$ Dr., Professor Adjunto do Departamento de Ciências Biológicas/FC/UNESP, Caixa Postal 473, CEP 17033-360, Bauru-SP.

E-mail: aloisio@fc.unesp.br

${ }^{4}$ Dr., Professor Emérito FCAV-UNESP, Via de Acesso Prof. Paulo D. Castellane, s/n. CEP 14.884-900, Jaboticabal-SP. Editor RBF.

E-mail: rbf@unesp.br
} 
tive crops and fruits of excellent quality. In this evolution, sum up the contribution of genetic improvement, which provided high-quality seed with reflects on cultural practices and propagation. Different harvesting and post-harvest techniques that result in improvements in the standard of quality of fruit exported to the European market and the U.S. are presented.

Index terms: Fruitculture advances, pineapple, papaya, passion fruit, production technology.

\section{AVANÇOS NACULTURADO ABACA- XIZEIRO NO BRASIL}

O Brasil é um dos grandes e tradicionais produtores de abacaxi (Ananas comosus (L.) Merril) no mundo, sendo que maior parte dos frutos é comercializada no mercado interno, na forma de fruta in natura. A produção está distribuída principalmente nos Estados do Norte e Nordeste, onde se cultiva a cultivar nacional Pérola ou Branco de Pernambuco, que por possuir uma acidez menos pronunciada e ser colhida em regiões quentes durante o ano inteiro, tem apresentado melhor aceitação pelo consumidor brasileiro. A cultivar Smooth Cayenne ou Hawai é produzida principalmente pelos Estados de Minas Gerais e São Paulo. Em função do aspecto de mercado mencionado, uma inovação resultante da parceria entre produtores e atacadistas tem sido observada, e consiste na comercialização dos frutos com melhor relação entre o teor de sólidos solúveis ( ${ }^{\circ}$ Brix) e acidez, em caixas de papelão ondulado na origem e com marca própria. Segundo Gutierrez (2011), a demanda do consumidor mais exigente por produtos saborosos está trazendo uma grande mudança na comercialização de abacaxis: a embalagem na origem. São inúmeras as vantagens, pois os frutos podem ser colhidos mais maduros e mais saborosos, porque não precisam resistir ao transporte a granel, a carga e a descarga são muito mais rápidas, ajudando a desafogar o tumultuado entreposto de São Paulo, e o produtor pode fixar sua marca na cabeça dos varejistas e consumidores finais.

Outro marco no sistema de produção do abacaxi no Brasil está na implantação da Produção Integrada do Abacaxizeiro no Estado do Tocantins (MATOS et al., 2006; MATOS et al., 2009), pois nas normas estão presentes alguns conceitos fundamentais para a sustentabilidade da cultura, principalmente para a pequena propriedade, ou seja, estímulo ao associativismo na comercialização; rastreabilidade do produto; monitoramento de pragas-chave, como a cochonilha de raiz, Dysmicoccus brevipes; produção das mudas por seccionamento do talo no controle preventivo da fusariose (Fusarium gutiforme); manejo cultural do mato com plantio de milheto (Pennisetum glaucum) e posterior uso de roçadeira manual nas entrelinhas da cultura; respeito à grade de defensivos registrados; uso de Equipamentos de Produção Individual (EPI); proteção das matas ciliares e nascentes. Este modelo deve avançar em todas as regiões produtoras e, para tanto, três dificuldades devem ser discutidas e sanadas, sendo duas de caráter técnico e uma política. As técnicas estão no uso proibitivo de herbicidas pré-emergentes em pós-plantio, ou seja, uma mudança na norma para o patamar de não recomendado, poderia facilitar a implantação do programa em áreas maiores de cultivo. Outra dificuldade reside no estudo de desempenho agronômico de alguns defensivos não registrados para a cultura e atualmente enquadrados no 'minor crops', mas com término de enquadramento legal para o $1^{\circ}$ semestre de 2012. O ponto de caráter político envolve todas as frutíferas e não apenas o abacaxizeiro, ou seja, está ligado à equivalência deste sistema de certificação nacional ao Globalgap e outros, a fim de termos um real estímulo ao aumento de adesões voluntárias no protocolo da Produção Integrada.

Outros avanços importantes no tradicional sistema de plantio em linhas duplas referem-se ao manejo do ciclo vegetativo da cultura, através do emprego de tecnologias que possam reduzir o ciclo cultural com o uso da indução floral artificial, porém sem redução do peso comercial dos frutos, que deve ser por volta de 1,8 kg. Entre estas tecnologias, podemos citar: aumento da densidade de plantio através de redução do espaçamento nas linhas de plantio; uso de pulverizações foliares em intervalos quinzenais, em alto volume, nas épocas quentes e chuvosas; plantio sobre filme plástico preto fixado mecanicamente no solo (Figura 1) e uso de cultivares resistentes à fusariose, 'Imperial' e 'Vitória' (CABRAL et al., 2009), lançadas recentemente pela Embrapa e da cultivar IAC Fantástico do Instituto Agronômico (SPIRONELLO, 2010; SPIRONELLO et al., 2011). O crescimento das áreas de plantio dessas cultivares depende da disponibilidade de mudas convencionais, que devem ser obtidas após um primeiro ciclo de mudas provenientes de cultura de tecidos, ou seja, o plantio inicial deve ser direcionado exclusivamente para produção de mudas. Nesta área, testes de campo com uso de fitorreguladores do grupo das morfactinas podem ser objeto interessante de pesquisas. Outra pesquisa muito importante para a cultura seria o projeto multidisciplinar de extração e purificação 
da bromelina, enzima proteolítica empregada nas áreas alimentícia e farmacêutica, e importada pelo Brasil da Alemanha e Suíça. Esta enzima poderia ser extraída do subproduto da indústria de processamento de sucos ou do talo das culturas em campo após a colheita das mudas. De acordo com Bertevello (2011), o Brasil possui alguns trabalhos de pesquisa para a extração da bromelina pelo processo de reação com etanol, porém há necessidade de se desenvolver tecnologia para a purificação da enzima. Além do aspecto tecnológico, há necessidade de se obter informações mercadológicas, tais como: quanto o Brasil importa de bromelina; qual o valor e a qualidade do produto importado; em quais setores da economia o produto é empregado?

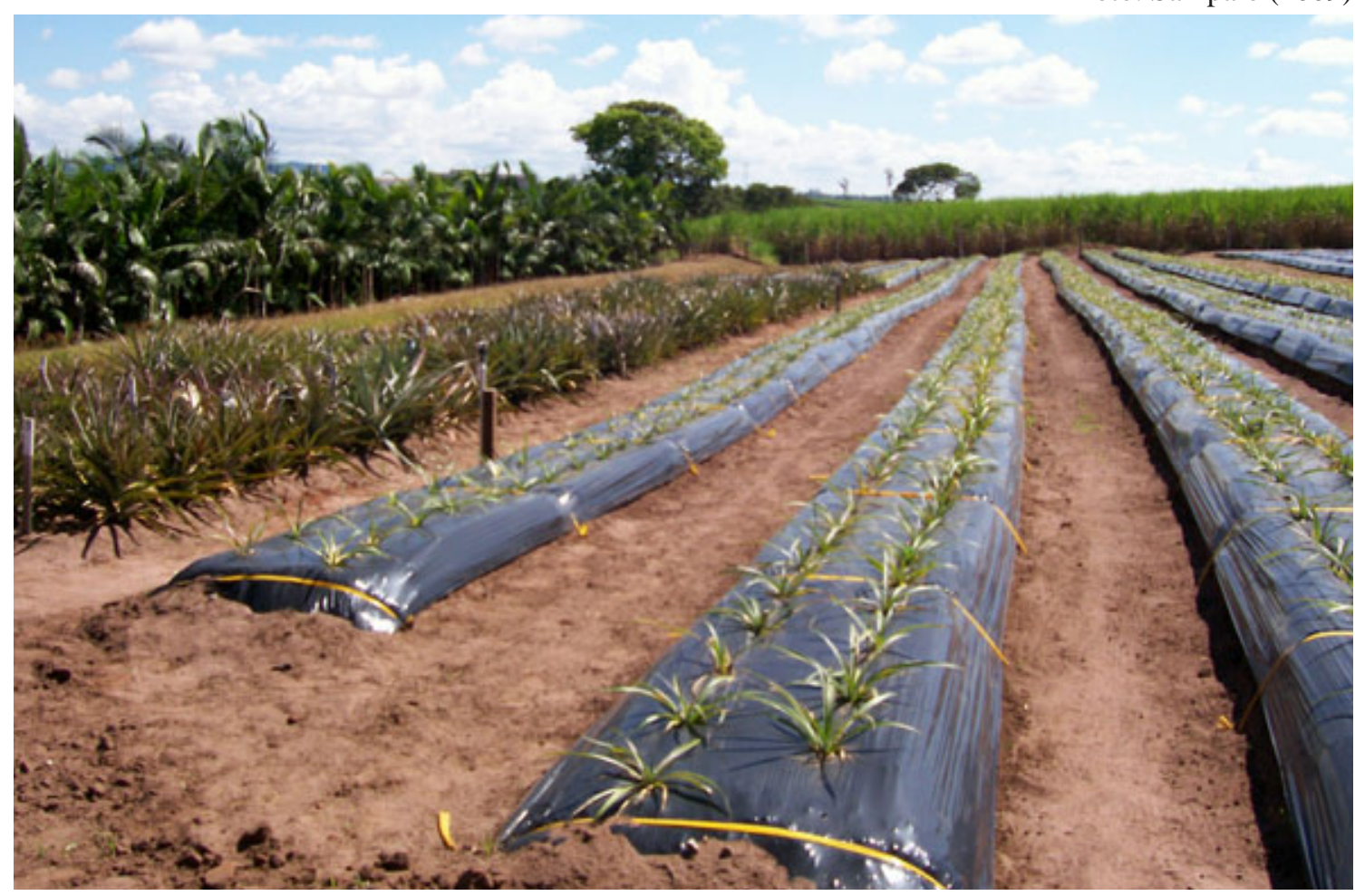

FIGURA 1- Cultivar IAC Gomo de Mel sob filme plástico preto em Rio Claro (SP).

\section{REFERÊNCIAS}

BERTEVELLO, L.C. Mercado, usos e extração da bromelina no Brasil. In: SIMPÓSIO BRASILEIRO DO ABACAXIZEIRO, 4., 2011, Bauru. Anais ... CABRAL, J. R. S.; MATOS, A. P.; JUNGHANS, D. T.; SOUZA, F. V. D. Pineapple Genetic Improvement in Brazil. Acta Horticulturae, The Hague, v.822, p. 39-46, 2009.

GUTIERREZ, A. S. D. Mudanças rápidas na comercialização do abacaxi: do granel para o embalado. São Paulo: CEAGESP, 2011.

MATOS, A. P. de; SOUZA, L. F. da S.; SANCHES, N. F.; ELIAS JR., J.; TEIXEIRA, F. A. Integrated pineapple production in Brazil: an R\&D project. Pineapple News, n.13, p. 16-17, 2006.
MATOS. A. P. de; SANCHES, N. F.; SOUZA, L. F. da S.; TEIXEIRA, F. A.; ELIAS JR., J.;SIEBENEICHLER, S. C. Cover crops on weed management in integrated pineapple production plantings. Acta Horticulturae, The Hague, n. 822, p. 155-160, 2009.

SPIRONELLO, A. Abacaxi. In: DONADIO. L.C. (Org.). História da fruticultura paulista. Jaboticabal: Sociedade Brasileira de Fruticultura, 2010. 400p.

SPIRONELLO, A.; SIQUEIRA, W.J.; MARTINS, A.L.M.; USBERTI FILHO, J.A.; CARVALHO, C.R.L.; BETTIOL NETO, J.E.; SIGRIST, J.M.M.; FERRARI, J.T.; LOUZEIRO, I.M. Avaliação do Híbrido de abacaxizeiro IAC Fantástico visando à indicação de cultivo. In: SIMPÓSIO BRASILEIRO DE ABACAXIZEIRO, 4., Bauru, 2011. Anais... 